Journal of research in health science

2017 № 2 (2), November-December

www.journalofresearch.org; info@journalofresearch.org

DOI $10.26739 / 2523-1243$

JOURNAL OF RESEARCH

IN HEALTHSCIENCE

ISSN Print: 2523-1243; ISSN Online: 2523-1251

\title{
Gene study of head and neck carcinoma
}

\section{Elmira Iriskulova}

Tashkent State Dental Institute Tashkent city Department of maxillo-facial surgery

\section{Email address:}

ir.el@rambler.ru (Elmira Iriskulova)

\section{To cite this article:}

Elmira Iriskulova. Gene study of head and neck carcinoma. Vol. 2, No. 2, 2017, pp. 12-14. DOI 10.26739/2523-1243

rnal of research in health science.

\section{doi http://dx.doi.org/10.26739/2523-1243/-2017-2-2-3}

\begin{abstract}
Uzbek ethnicity with malignant tumors of maxillo-facial area. Results of the research showed that developing of malignant tumors of maxillofacial area involving face skin and oral mucosa was associated with the carrier of a heterozygous Arg/ Pro genotype.
\end{abstract}

Keywords: maxillo-facial area, neoplasm, genetic aberration, genotype, polymorphic marker, carcinoma, Uzbek ethnicity, amplification, heterozygous.

Neoplasms of maxillo-facial area involving face skin and oral mucosa according to numerous studies have a growing trend. Despite the visual accessibility of the localization over $70 \%$ of patients with malignant neoplasms are diagnosed in last clinical stages.

As well known, the gene TP53 plays an important role in regulation of cell cycle and maintenance of genome stability, preventing mutations. The decrease of the gene TP53 expression or its mutation is probably one of the most prevailing genetic aberrations leading to cancer. The most frequent polymorphism of the gene TP53 in the codon 72 of the exon 4 (dbSNP ID: rs1042522) designated as Arg72Pro may influence on the development risk and/or prognosis of many cancer localizations, as it is reported $1,2,3,4$.

The purpose of the study is to investigate the distribution features of genotypes of polymorphic marker Arg72Pro of the gene TP53 in patients with carcinoma of Uzbek ethnicity.

Materials and methods of research. The main group $(n=117)$ consisted of patients of Uzbek ethnicity with carcinoma, among them there were 90 male and 27 female patients. The average age is $54.3+8.6$ years old. The control group $(n=70)$ consisted of volunteers of Uzbek ethnicity with average age $51.0+6.2$ years 
old with no oncologic diseases reported.

Carcinomas were diagnosed on the base of cytomorphological researches, inconformity between the clinical symptoms and the morphological results were not observed.

The isolation of genomic DNA was performed from whole peripheral blood with the device Diatom DNA Prep 200 ("Isogen Laboratory", Russia) according to the producer protocol. The polymerase chain reaction was performed on amplifier GeneAmp ${ }^{\circledR}$ PCR System 9700 (Applied Biosystems, USA) using set for genotyping on polymorphic marker Arg72Pro of the gene TP53 (GenTest, Russia).

The conditions of amplification:

\begin{tabular}{|c|c|c|}
\hline The first denaturation & 10 cycles & 30 cycles \\
\hline \multirow{3}{*}{$95^{\circ} \mathrm{C}-5$ min } & $94^{\circ} \mathrm{C}-20 \mathrm{sec}$ & $94^{\circ} \mathrm{C}-20 \mathrm{sec}$ \\
\cline { 2 - 3 } & $\mathrm{TD}^{*}-50 \mathrm{sec}$ & $64^{\circ} \mathrm{C}-50 \mathrm{sec}$ \\
\cline { 2 - 3 } & $72^{\circ} \mathrm{C}-20 \mathrm{sec}$ & $72^{\circ} \mathrm{C}-20 \mathrm{sec}$ \\
\hline
\end{tabular}

* - TD - Touchdown PCR

Detection of the amplification results was carried out by horizontal electrophoresis in a $1 \%$ agarose gel at field strength of $\sim 15 \mathrm{~V} / \mathrm{cm}$ for 30 minutes. The gel was stained with a solution of ethidium bromide followed by viewing in the ultraviolet spectrum (wave length 254 $\mathrm{nm}$ ) on a transilluminator. The obtained results were documented by photographing.

To determine the genotype, subsequent restriction of the amplification products was performed using the restriction enzyme HspAI at $50^{\circ} \mathrm{C}$ for 2 hours.

Thus, by gel electrophoresis, a $252 \mathrm{bp}$ fragment was found that matched the amplified DNA fragments containing the polymorphic sequences of Arg72Pro of the TP53 gene.

To determine the genotype, restriction of amplification products was performed using the restriction enzyme TP53Arg72Pro. The DNA fragment containing the Arg/Arg genotype was 252 bp long. The fragment containing the Pro/Pro genotype was separated by a restriction enzyme into fragments of size 228 and 24 bp. Fragments of 252, 228, and $24 \mathrm{bp}$ in size corresponded to the heterozygous genotype Arg/Pro.

The distribution of genotypes in both groups corresponded to the HardyWeinberg law. For comparison of genotypes, the standard Pearson ?2 test was used. The relative risk (odds ratio, OR) of the disease in the carrier of a particular genotype was calculated according to the multi plicative inheritance model.

Results of the study. The frequency of distribution of the Arg72Pro genotypes polymorphism of the TP53 gene in patients with carcinoma of Uzbek ethnicity of Arg/Arg was 0,11, Arg/Pro was 0,68, Pro/Pro was 0,$21 ; X^{2}=99,308, p=0,000$. In healthy volunteers, the Arg/Arg:Arg/ Pro:Pro/Pro ratio was $0,27: 0,52: 0,21, \mathrm{X}^{2}=$ $21,57, \mathrm{p}=0,000$.

The heterozygous genotype dominated in patients with carcinoma, as well as in the control group. Nevertheless, the number of persons with a heterozygous genotype was significantly higher in the main group - 0,68 , in the control group $-0,52(p=0,03)$. The homozygous Arg/ Arg genotype was rare in patients with carcinoma - 0,11 in the main group and 0,27 in the control group $(p=0,005)$. The increased risk of developing of carcinoma was associated with the accumulation of the Arg/Pro genotype [OR: 1,93 (95\% CI:1,05-3,55), while the carrier of Arg/Arg genotype was associated with a decrease in this risk [OR:0,34 (95\% CI:0,15-0,73)]. 
Elmira Iriskulova. Gene study of head and neck carcinoma.

Conclusions. Thus, the results of the Pro genotype, which, nevertheless, was study showed that an increased risk of occurred quite often in the healthy group. developing of carcinoma was associated Carrier of Arg/Arg genotype was associated with the carrier of a heterozygous Arg/ with decrease in the risk of the disease.

\section{References}

[1] Thiagalingam SA. Cascade of modules of a network defines cancer progression. Cancer Res. 2006; 66 (15):7379-7385.

[2] Weinberg R.A. Mechanisms of malignant progression. Carcinogenesis 2008; 29:1092-1105.

[3] Gupta PB, Chaffer CL, Weinberg RA. Cancer stem cells: mirage or reality. Nat. Med. 2009; 15:1010-1012.

[4] Imyanitov YN. Molecular mechanisms of tumor growth. Questions of Oncology, 2010; 2:117-128. 